\title{
Evaluasi Quantity Spare Parts dengan Pendekatan EOQ (Economic Order Quantity) PT. Kobexindo Tractors. Tbk Cabang Pekanbaru
}

\author{
Dedi Dermawan, Wahyu Hidayah \\ Program Studi Teknik Industri Fakultas Teknik Universitas Muhammadiyah Riau \\ Jl. Tuanku Tambusai Ujung Pekanbaru \\ E-mail :dedi@umri.ac.id
}

\begin{abstract}
Abstrak
Kebutuhan Spare Parts unit Froklift Truck atau yang biasa disebut dengan Reach Truck saat ini dihadapkan pada sebuah risiko, tidak dapat memenuhi keinginan para pelanggannya. Persediaan bisa muncul ketika ada kebutuhan dan adanya sebuah perencanaan untuk mengadakan persediaan. Akibat yang ditimbulkan ketika sebuah perusahaan melakukan pengadaan tanpa ada perencanaan yaitu seringterjadinya tidak terjual akibat rendahnya jumlah permintaan sehingga mengakibatkan kinerja perusahaan menurun dan biaya yang tinggi. Teknik pengendalian persediaan akan memperkirakan berapa jumlah optimal tingkat persediaan yang diharuskan, serta kapan saatnya mulai mengadakan pemesanan kembali (reorder point). Perencanaan dengan pendekatan EOQ (Economic Order Quantity) merupakan solusi perencaaan persediaan yang optimal dalam memenuhi kebutuhan persediaan tetap lancar.
\end{abstract}

Kata kunci : Spare Part, Persediaan, EOQ (Economic Order Quantity)

\section{Pendahuluan}

Pada saat ini perkembangan dunia industri peralatan tenaga pengangkut dan pengangkat seperti Forklift, Handpallet, Pallet Mover, sedang berkembang cukup pesat dengan persaingan ketat antara masing-masing distributor. Tentunya hal ini juga berpengaruh terhadap kebutuhan pasar, baik dalam kebutuhan Unit, Spareparts, dan kebutuhan jasa service atau maintenance. Pada banyak perusahaan, terutama perusahaan yang bergerak dibidang penjualan, nilai aset terbesar ada pada persediaan barang dagang tersebut. Tanpa adanya persediaan, perusahaan akan dihadapkan pada sebuah risiko, tidak dapat memenuhi keinginan para pelanggannya.

Pada bulan-bulan tertentu PT. Kobexindo Tractors Tbk mengalami kehabisan beberapa persediaan barang yang akan dijual. Jumlah persediaan barang yang ada terlalu sedikit dibandingkan dengan jumlah permintaan konsumen. Perusahaan sendiri menentukan kuantitas pemesanan persediaan barang dagang dan periode pemesanan berdasarkan pengalaman dan intuisi. Jika perusahaan memenuhi permintaan konsumen pada saat kehabisan persediaan, maka perusahaan akan mengeluarkan biaya yang lebih besar. Kekurangan jumlah persediaan dan waktu yang lama ( Indent) dalam memenuhi kebutuhan konsumen menyebabkan mereka kecewa dan berimbas kepada kepercayaan terhadap penjualan unit sehingga mereka bisa beralih ke perusahaan lain dengan produk sejenis, dan hal ini mengurangi kesempatan perusahaan untuk memperoleh keuntungan.

Agus Ristono (2008) menyatakan "persediaan pengamanan atau safety stock adalah persediaan yang dilakukan untuk mengantisipasi unsur ketidakpastiaan permintaan dan penyediaan. Apabila persediaan pengamanan tidak mampu mengantisipasi ketidakpastian tersebut, akan terjadi kekurangan persediaan (stockout)."

Safety stock bertujuan untuk menentukan berapa besar stock yang dibutuhkan selama masa tenggang untuk memenuhi besarnya permintaan.

Jumlah safety stock yang sesuai dalam kondisi tertentu sangat tergantung pada factor-faktor sebagai berikut:"

1. Rata-rata tingkat permintaan dan rata-rata masa tenggang

2. Variabilitas permintaan dan masa tenggang

3. Keinginan tingkat pelayanan yang diberikan.

Model EOQ pertama kali diperkenalkan oleh FW. Harris pada tahun 1915. Persediaan dianggap mempunyai dua macam biaya, biaya pesan/ ordering costl set up cost dan biaya simpan/ 
carring cost/ holding cost. Heizer dan Render (2005) menyatakan EOQ merupakan salah satu teknik pengendalian persediaan tertua dan paling terkenal. Teknik ini relative mudah digunakan, tetapi didasarkan pada beberapa asumsi:

1. Tingkat permintaan diketahui dan bersifat konstan

2. Lead time, yaitu waktu antara pemesanan dan penerimaan pesanan, diketahui, dan bersifat konstan.

3. Tidak mungkin diberikan diskon

4. Biaya variabel yang muncul hanya biaya pemasangan atau pemesanan dan biaya penahanan atau penyimpanan persediaan sepanjang waktu.

5. Keadaan kehabisan stok (out of stock) dapat dihindari sama sekali bila pemesanan dilakukan pada waktu yang tepat.

Menghitung Economic Order Quantity dapat dilakukan dengan menggunakan persamaan sebagai berikut.

$$
E O Q=\frac{\sqrt{2 D S}}{H}
$$

Dimana :

$$
\begin{array}{ll}
\mathrm{D}= & \text { Permintaan selama setahun }(\mathrm{Pcs}) \\
\mathrm{S}= & \text { Biaya pemesanan }(\mathrm{Rp}) \\
\mathrm{H}= & \text { Biaya penyimpanan }(\mathrm{Rp})
\end{array}
$$

Total Inventory Cost berguna untuk mengetahui berapa biaya total dalam setiap melakukan pemesanan suku cadang. Menghitung Total Inventory Cost dapat dilakukan dengan menggunakan persamaan sebagai berikut.

$$
\mathrm{TIC}=\frac{D}{Q}(S)+\frac{Q}{2}(H)+D x C
$$

Dimana :

$$
\begin{array}{lll}
\mathrm{D}= & \text { Permintaan selama setahun }(\mathrm{Pcs}) \\
\mathrm{Q}= & \text { EOQ }(\text { Pcs }) \\
\mathrm{S}= & \text { Biaya pemesanan }(\mathrm{Rp}) \\
\mathrm{H}= & \text { Biaya penyimpanan }(\mathrm{Rp}) \\
\mathrm{C}= & \text { Harga per satuan }(\mathrm{Rp})
\end{array}
$$

\section{Methodologi}

Tahapan yang disusun untuk menyelesaikan permasalah persediaan pada PT. Kobexindo Tractor. Tbk ini meliputi :

Tahap 1 : Melakukan Klasifikasi Ranking, untuk mengetahui kelas atau tingkat dari suatu barang tanpa mengabaikan barang yang lain dalam suatu inventory. Perusahaan membagi persediaan suku cadang dalam lima kelas berdasarkan dari suatu nilai persediaan dan tingkat penjualan suatu barang. Tahap 2 : Melakukan Peramalan (Forecasting) berdasarkan data historis tahun lalu

Tahap 3 : Perhitungan Safety Stock dan penentuan R order Point
Tahap 4 : Penentuan Economic Order Quantity (EOQ) dan Total Inventory Cost (TIC)

\section{Hasil dan Pembahasan}

\subsection{Klasifikasi Ranking}

Klasifikasi ranking yang dilakukan menggunakan data yang telah ditetapkan oleh perusahaan. Pengujian menggunakan lima ranking dan suku cadang yang di uji adalah suku cadang prioritas dari tiap-tiap rangking tersebut. Adapun klasifikasi ranking suku cadang yang akan di uji adalah sebagai berikut.

Tabel 1.

Keterangan Ranking

\begin{tabular}{cll}
\hline Ranking & \multicolumn{1}{c}{ Movement } & \multicolumn{1}{c}{ Keterangan } \\
\hline 1 & 1 Bulan & Very Fast Moving \\
2 & 2 Bulan & Fast Moving \\
3 & 3-5 Bulan & Medium Moving \\
4 & 6-9 Bulan & Low Moving \\
5 & 10-12 Bulan & Very Low Moving \\
\hline
\end{tabular}

Tabel 2.

Klasifikasi Ranking

\begin{tabular}{cclc}
\hline $\begin{array}{c}\text { Kode } \\
\text { Part }\end{array}$ & Part Number & \multicolumn{1}{c}{ Part Name } & Ranking \\
\hline A1 & 50024369 & Battery Acid Water & 1 \\
A2 & 50006457 & Seal Kit & 2 \\
A3 & 50038984 & Load Wheel & 3 \\
A4 & 50030509 & Drive Wheel & 4 \\
A5 & 50033741 & Chain Steering & 5 \\
\hline
\end{tabular}

\subsection{Peramalan (Forecasting)}

Data Penjualan Aktual Suku Cadang 12 Bulan Terakhir mulai bulan Oktober 2016 s.d September 2017:

Tabel 3.

Data Kebutuhan Parts Bulan Oktober 2016 - September 2017

\begin{tabular}{ccccccccccccc}
\hline $\begin{array}{c}\text { Kode } \\
\text { Part }\end{array}$ & 10 & 11 & 12 & 1 & 2 & 3 & 4 & 5 & 6 & 7 & 8 & 9 \\
\hline A1 & 20 & 17 & 15 & 8 & 18 & 8 & 10 & 13 & 12 & 10 & 18 & 8 \\
A2 & 6 & 4 & 9 & 4 & 7 & 3 & 5 & 8 & 4 & 8 & 7 & 5 \\
A3 & 4 & 0 & 0 & 2 & 0 & 0 & 4 & 3 & 2 & 8 & 0 & 2 \\
A4 & 2 & 1 & 4 & 0 & 0 & 2 & 0 & 1 & 0 & 4 & 2 & 0 \\
A5 & 0 & 0 & 0 & 0 & 0 & 2 & 0 & 0 & 0 & 4 & 1 & 0 \\
\hline
\end{tabular}

Peramalan dilakukan dengan menggunakan software WIN QSB.

Dari data penjualan yang diperoleh, lima item suku cadang yang telah dikumpulkan diuji dengan 10 metode peramalan yang terdapat pada software WIN QSB. Dari 10 metode, hanya 1 metode yang digunakan, yakni metode dengan nilai error terkecil. Berikut ini adalah perbandingan nilai error 
terkecil dari 10 metode dari pengolahan data pada item Pad Set FR.

Tabel 4.

Perbandingan Nilai Error Terkecil Dari 10 Metode Pada Item Battery Acid Water menggunakan Software WIN QSB

\begin{tabular}{clccc}
\hline & \multicolumn{1}{c}{ Metode } & \multicolumn{3}{c}{ Nilai Error } \\
No & \multicolumn{1}{c}{ MAD } & MSE & MAPE \\
\hline 1 & Simple Average (SA) & 4.27 & 23.97 & 42.06 \\
2 & $\begin{array}{l}\text { Moving Average (MA) } \\
5.27\end{array}$ & 40.36 & 49.08 \\
3 & $\begin{array}{l}\text { Weighted Moving } \\
\text { Average (WMA) }\end{array}$ & 5.27 & 40.36 & 49.08 \\
4 & $\begin{array}{l}\text { Moving Average with } \\
\text { Linear Trend (MAT) }\end{array}$ & 5.27 & 40.36 & 49.08 \\
5 & $\begin{array}{l}\text { Single Exponential } \\
\text { Smoothing (SES) }\end{array}$ & 5.27 & 40.36 & 49.08 \\
6 & $\begin{array}{l}\text { Single Exponential } \\
\text { Smoothing With Trend } \\
7\end{array}$ & & & \\
(SEST) & $\begin{array}{l}\text { Double Exponential } \\
\text { Smoothing (DES) }\end{array}$ & 5.36 & 119.09 & 80.25 \\
8 & $\begin{array}{l}\text { Double Exponential } \\
\text { Smoothing With Trend }\end{array}$ & & 40.36 & 49.08 \\
9 & $\begin{array}{l}\text { (DEST) } \\
\text { Adaptive Exponential }\end{array}$ & 5.27 & 40.36 & 49.08 \\
& $\begin{array}{l}\text { Smoothing (AES) } \\
10\end{array}$ & 5.27 & 40.36 & 49.08 \\
\hline & Linear Regression (LR) & 2.99 & 14.42 & 26.26 \\
\hline
\end{tabular}

Dari pengujian yang dilakukan dengan 10 metode peramalan, maka diperoleh perbandingan nilai error diatas, metode yang dipilih adalah Linier Regression With Time pada nomor 10 karena memiliki nilai error terkecil. Adapun hasil peramalan dari pegolahan data penjualan aktual 12 bulan terakhir dengan metode Linier Regression With Time adalah sebagai berikut.

Tabel 5.

Hasil Peramalan Oktober 2016-September 2017 Metode Linier Regression

\begin{tabular}{cccccc}
\hline Bulan & $\begin{array}{c}\text { Battery } \\
\text { Acid } \\
\text { Water }\end{array}$ & $\begin{array}{c}\text { Seal } \\
\text { Kit }\end{array}$ & $\begin{array}{c}\text { Load } \\
\text { Wheel }\end{array}$ & $\begin{array}{c}\text { Drive } \\
\text { Wheel }\end{array}$ & $\begin{array}{c}\text { Chain } \\
\text { Steering }\end{array}$ \\
\hline 10 & 10 & 6 & 3 & 1 & 1 \\
11 & 9 & 6 & 3 & 1 & 2 \\
12 & 9 & 6 & 3 & 1 & 2 \\
1 & 8 & 6 & 4 & 1 & 2 \\
2 & 8 & 6 & 4 & 1 & 2 \\
3 & 7 & 6 & 4 & 1 & 2 \\
4 & 6 & 6 & 4 & 1 & 2 \\
5 & 6 & 7 & 4 & 1 & 2 \\
6 & 5 & 7 & 4 & 1 & 2 \\
7 & 5 & 7 & 5 & 1 & 2 \\
8 & 4 & 7 & 5 & 1 & 3 \\
9 & 4 & 7 & 5 & 1 & 3 \\
\hline
\end{tabular}

3.3 Perhitungan Safety Stock, Reorder Point, EOQ dan Total Inventory Cost

\section{A. Safety Stock}

Dengan menggunakan perkiraan atau asumsi bahwa perusahaan dapat memenuhi kebutuhan suku cadang sebanyak $95 \%$ dan persediaan cadangan 5\%, maka diperoleh dua tabel normal sebesar 1,65 deviasi standar dari rata-rata. Menghitung Safety Stock dengan rencana service level yaitu $95 \%$ sehingga $\mathrm{z}=1$. 65. Berikut ini adalah perhitungan Safety Stock pada item :

Tabel 6.

Rekapitulasi Safety Stock Tiap Item dalam periode $\mathrm{n}=12$ Bulan

\begin{tabular}{|c|c|c|c|c|c|c|}
\hline \multirow[b]{2}{*}{ Bulan } & \multicolumn{5}{|c|}{ Part Name(Unit) } & \\
\hline & $\begin{array}{c}\text { Battery } \\
\text { Acid } \\
\text { Water }\end{array}$ & $\begin{array}{c}\text { Seal } \\
\text { Kit }\end{array}$ & $\begin{array}{c}\text { Load } \\
\text { Wheel }\end{array}$ & $\begin{array}{l}\text { Drive } \\
\text { Wheel }\end{array}$ & $\begin{array}{c}\text { Chain } \\
\text { Steering }\end{array}$ & \\
\hline 10 & 10 & 6 & 3 & 1 & 1 & \\
\hline 11 & 9 & 6 & 3 & 1 & 2 & \\
\hline 12 & 9 & 6 & 3 & 1 & 2 & \\
\hline 1 & 8 & 6 & 4 & 1 & 2 & \\
\hline 2 & 8 & 6 & 4 & 1 & 2 & \\
\hline 3 & 7 & 6 & 4 & 1 & 2 & \\
\hline 4 & 6 & 6 & 4 & 1 & 2 & \\
\hline 5 & 6 & 7 & 4 & 1 & 2 & $\overrightarrow{0}$ \\
\hline 6 & 5 & 7 & 4 & 1 & 2 & \\
\hline 7 & 5 & 7 & 5 & 1 & 2 & \\
\hline 8 & 4 & 7 & 5 & 1 & 2 & \\
\hline 9 & 4 & 7 & 5 & 1 & 2 & \\
\hline Total & 81 & 77 & 48 & 12 & 25 & \\
\hline Ave & 7 & 6 & 4 & 1 & 2 & \\
\hline $\begin{array}{l}\text { Srv } \\
\text { Lvl }\end{array}$ & & & $95 \%$ & & & \\
\hline $\mathrm{Z}$ & & & 1.65 & & & \\
\hline $\mathrm{N}$ & & & 12 & & & \\
\hline SD & 6 & 6 & 4 & 1 & 2 & \\
\hline SS & 10 & 10 & 6 & 2 & 3 & 31 \\
\hline
\end{tabular}

\section{B. Re-order Point}

Untuk Lead Time perusahaan menetapkan 7 hari dan "d" = 0,29 ( Ave $7: 24$ hari $=0.29$ ) setiap melakukan order barang. Pada tabel 7 dapat dilihat rekapitulasi Reorder Point masing-masing item part.

\section{Economic Order Quantity (EOQ)}

Pada tabel 8 terlihat rekapitulasi perhitungan Economic Order Quantity pada masing-masing item part.

\section{Biaya Persediaan Total (Total Inventory Cost)}

Biaya persediaan total berguna untuk mengetahui berapa biaya total dalam suatu periode akuntansi setiap melakukan pemesan suku cadang. Tabel 8 berikut ini adalah rekapitulasi perhitungan Total Inventory Cost pada masing-masing item. 
Tabel 7.

Hasil Rekapitulasi Perhitungan Reorder Point

\begin{tabular}{cccccc}
\hline \multirow{2}{*}{ Bulan } & $\begin{array}{c}\text { Battery } \\
\text { Acid } \\
\text { Water }\end{array}$ & $\begin{array}{c}\text { Seal } \\
\text { Kit }\end{array}$ & $\begin{array}{c}\text { Load } \\
\text { Wheel }\end{array}$ & $\begin{array}{c}\text { Drive } \\
\text { Wheel }\end{array}$ & $\begin{array}{c}\text { Chain } \\
\text { Steering }\end{array}$ \\
\hline 10 & 10 & 6 & 3 & 1 & 1 \\
11 & 9 & 6 & 3 & 1 & 2 \\
12 & 9 & 6 & 3 & 1 & 2 \\
1 & 8 & 6 & 4 & 1 & 2 \\
2 & 8 & 6 & 4 & 1 & 2 \\
3 & 7 & 6 & 4 & 1 & 2 \\
4 & 6 & 6 & 4 & 1 & 2 \\
5 & 6 & 7 & 4 & 1 & 2 \\
6 & 5 & 7 & 4 & 1 & 2 \\
7 & 5 & 7 & 5 & 1 & 2 \\
8 & 4 & 7 & 5 & 1 & 2 \\
9 & 4 & 7 & 5 & 1 & 2 \\
Average & 7 & 6 & 4 & 1 & 7 \\
SS & 10 & 10 & 6 & 2 & 3 \\
ROP & 12 & 11 & 7 & 2 & 4 \\
\hline
\end{tabular}

Tabel 8.

Hasil Rekapitulasi Perhitungan Economic Order Quantity Pada Tiap Item.

\begin{tabular}{lrrrrrr}
\hline \multicolumn{1}{c}{$\begin{array}{c}\text { Part } \\
\text { Name }\end{array}$} & Ave & Total & $\begin{array}{r}\text { Biaya } \\
\text { pesan }\end{array}$ & $\begin{array}{r}\text { Biaya } \\
\text { simpan }\end{array}$ & EOQ & AVE \\
\hline $\begin{array}{l}\text { Battery } \\
\text { Acid }\end{array}$ & 7 & 81 & 15.000 & 1.000 & 49 & 4 \\
$\begin{array}{l}\text { Water } \\
\text { Seal Kit }\end{array}$ & 6 & 77 & 2.500 & .500 & 28 & 2 \\
$\begin{array}{l}\text { Load } \\
\text { Wheel }\end{array}$ & 4 & 48 & 80.000 & 2.500 & 25 & 2 \\
$\begin{array}{l}\text { Drive } \\
\text { Wheel }\end{array}$ & 1 & 12 & 95.000 & 12.500 & 14 & 1 \\
$\begin{array}{l}\text { Chain } \\
\text { Steering }\end{array}$ & 2 & 25 & 0.000 & 12.500 & 13 & 1 \\
Total & 20 & 243 & 32.500 & 9.000 & 128 & 11 \\
\hline
\end{tabular}

Tabel 9.

Hasil Rekapitulasi Perhitungan Total Inventory Cost (Satuan Rupiah)

\begin{tabular}{|c|c|c|c|c|c|}
\hline No & $\begin{array}{c}\text { Part } \\
\text { Name }\end{array}$ & $\begin{array}{l}\text { Biaya } \\
\text { pesan }\end{array}$ & $\begin{array}{l}\text { Biaya } \\
\text { simpan }\end{array}$ & EOQ & TIC \\
\hline 1 & $\begin{array}{l}\text { Battery } \\
\text { Acid } \\
\text { Water }\end{array}$ & 15.000 & .000 & 49 & 105 \\
\hline 2 & Seal Kit & 2.500 & 500 & 28 & 130.913 .874 \\
\hline 3 & $\begin{array}{l}\text { Load } \\
\text { Wheel }\end{array}$ & 80.000 & 12.500 & 25 & 302.709 .839 \\
\hline 4 & $\begin{array}{l}\text { Drive } \\
\text { Wheel }\end{array}$ & 95.000 & 12.500 & 14 & 110.568 .819 \\
\hline \multirow[t]{2}{*}{5} & $\begin{array}{l}\text { Chain } \\
\text { Steering }\end{array}$ & 40.000 & 12.500 & 13 & 196.408 .114 \\
\hline & Total & 232.500 & & 128 & 845.949 .941 \\
\hline
\end{tabular}

\section{Simpulan}

Dari beberapa langkah yang telah dilakukan dapat disimpulkan bahwa :

1. Klasifikasi Rangking Part yang dilakukan perencanaan meliputi : [1]. Battery Acid Water, [2]. Seal Kit, [3]. Load Wheel [4]. Drive Wheel, [5]. Chain Steering.

2. Setelah dilakukan peramalan terhadap kebutuhan part maka diperoleh perbandingan sbb :

Tabel 10.

Perbandingan Data Penjualan Sebelum Dan Sesudah Peramalan

\begin{tabular}{clcc}
\hline No & \multicolumn{1}{c}{ Part Name } & \multicolumn{2}{c}{ Total Penjualan Pertahun } \\
& & $\begin{array}{c}\text { Sebelum } \\
\text { Peramalan }\end{array}$ & $\begin{array}{c}\text { Sesudah } \\
\text { Peramalan }\end{array}$ \\
\hline 1 & Battery Acid Water & 157 & 49 \\
2 & Seal Kit & 70 & 28 \\
3 & Load Wheel & 25 & 25 \\
4 & Drive Wheel & 16 & 14 \\
5 & Chain Steering & 7 & 13 \\
\hline
\end{tabular}

3. Hasil Perencanan Persediaan dengan metode EOQ dan TIC :

Tabel 11.

Perhitungan Metode EOQ

\begin{tabular}{clcccc}
\hline No & \multicolumn{1}{c}{ Part Name } & Rank & SS & ROP & EOQ \\
\hline 1 & Battery Acid Water & 1 & 10 & 12 & 49 \\
2 & Seal Kit & 2 & 10 & 11 & 28 \\
3 & Load Wheel & 3 & 6 & 7 & 25 \\
4 & Drive Wheel & 4 & 2 & 2 & 14 \\
5 & Chain Steering & 5 & 3 & 4 & 13 \\
\hline
\end{tabular}

\section{Daftar Pustaka}

[1]. Buffa, Elwood S. 2002. Manajemen Produksi/Operasi, edisi 6, Jilid II. Jakarta: Erlangga.

[2]. Bowersox, Donald J. 2002. Manajemen Logistik. Jilid I. Jakarta: PT. Bumi Aksara.

[3]. Ferdinand, Prof. Dr. Augusty, MBA. 2006. Metode Penelitian Manajemen. Semarang : Badan Penerbit Undip

[4]. Heizer, Jay dan Barry Render. 2005. Operations Management : Manajemen Operasi. Jakarta : Salemba Empat.

[5]. Indrajid, Ricardus Eko, 2005, Strategi Manajemen Pembelian dan Suply Chain, Pendekatan Manajemen Terkini, Untuk Persaingan Global, Jakarta, Grasindo Indonesia 
ISSN: 2354-6751

[6]. Marzuki. 2005. Metodologi Riset (Panduan Penelitian Bidang Bisnis dan Sosial). Yogyakarta: Ekonisia.

[7]. Pardede, M. Pontas. 2007, Manajemen Operasi Dan Produksi, Teori, Model, Dan Kebijakan, Edisi Revisi, Andi, Yogyakarta

[8]. Ristono, Agus. 2008. Manajemen Persediaan. Yogyakarta: Graha Ilmu 